\title{
Viherlannoitusnurmella nopeaan sokerijuurikkaan kasvuun
}

\author{
Hanne Riski ${ }^{1)}$, Marja Turakainen ${ }^{1)}$ ja Susanna Muurinen ${ }^{1)}$ \\ 1) Sokerijuurikkaan Tutkimuskeskus, Toivonlinnantie 518, 21500 Piikkiö \\ hanne.riski@nordisugar.com
}

\section{Tiivistelmä}

Suomessa sokerijuurikasta viljellään juurikas-vilja -viljelykierrossa tai ilman viljelykiertoa. Karjattomilla tiloilla nurmen sijoittaminen viljelykiertoon koetaan ongelmaksi. Ratkaisuna voisi olla nurmikierron järjestäminen viherlannoitusnurmen avulla.

Kokeen tavoitteena oli selvittää yksivuotisen timotei-apila -nurmen viherlannoitusvaikutusta sokerijuurikkaan sadon määrään ja sen laatuun sekä maan kasvukuntoon. Viherlannoitusnurmi oli perustettu vuonna 2007 Tenholaan tilakokeena. Verranteena toimi tavallisessa viljelyssä ollut lohko, jossa edellisvuonna oli kasvanut mallasohra. Molemmat koelohkot jaettiin kahteen kaistaan, joille annettiin kylvön yhteydessä joko $90 \mathrm{~kg} \mathrm{~N} / \mathrm{ha}$ tai $120 \mathrm{~kg} \mathrm{~N} / \mathrm{ha}$. Kaistoista tehtiin taimettumis- ja peittävyyshavainnnot sekä seurattiin typen riittävyyttä lehtivihreämittauksilla. Lisäksi maan kuntoa arvioitiin kuoppatestin avulla sekä mittaamalla pintamaan vedenjohtavuus. Viherlannoituksen vaikutusta tuholaisvioituksiin havainnoitiin eri siemenkäsittelyillä. Kasvustosta havainnoitiin Ramularia- lehtilaikkutaudin vioitusmäärä. Juurisadon määrä ja sokeri-, aminotyppi-, kalium- ja natriumpitoisuus sekä saanto-\% määritettiin lopullisesta sadosta.

Taimettuminen oli nopeampaa ja tasaisempaa viherlannoituslohkolla kuin tavallisella lohkolla samoin kuin myös kasvuston peittävyys oli suurempi. SPAD-arvot olivat viherlannoituslohkolla koko kasvukauden korkeammat kuin ilman viherlannoitusta olleella lohkolla. Mineraalitypen määrä kasvukaudella oli viherlannoituslohkolla 70 kg/ha ja tavallisella 56 kg/ha. Lehtivihreämittaustuloksista ja liukoisen typen pitoisuudesta voidaan päätellä, että viherlannoitus lisäsi kasveille käyttökelpoisen typen määrää kasvukauden aikana. Viherlannoitus tuotti alhaisemmalla typpilannoituksella 4500 kg/ha ja korkeammalla typpilannoituksella 9800 kg/ha korkeammman juurisadon kuin tavallinen lannoitus. Ramularia lehtilaikkutautia esiintyi huomattavasti vähemmän viherlannoituslohkolla.

Tuloksista voidaan päätellä, että yksivuotinen viherlannoitus soveltuu hyvin sokerijuurikkaan viljelykiertoon ja se hyötyy viherlannoituksesta. Juurikkaalla saadaan merkittävä sadonlisäys, kun maan typpitaloutta parannetaan viherlannoitusnurmella. Toisaaltaan viherlannoituksella on edullinen vaikutus maan kasvukuntoon. Ramularian torjunnan tarve vähenee.

Asiasanat: sokerijuurikas, viherlannoitus, sato, SPAD, liukoinen typpi, pintamaan vedenjohtavuus 


\section{Johdanto}

Pitkässä yksipuolisessa viljelyssä sokerijuurikkaan sadon määrä ja laatu alenevat maan kasvukunnon huonontuessa ja siksi tarve monipuoliseen viljelykiertoon siirtymiseen juurikkaanviljelyssä on kasvanut. Juurikkaan taloudellisen tuloksen parantamiseksi myös kiinnostus maan ravinnereservien tehokkaaseen ja kestävään hyödyntämiseen sekä lannoituskustannusten alentamiseen on lisääntynyt.

Viherlannoituksella tarkoitetaan eri kasvilajien viljelyä niin, että niiden vesipitoinen, vihreä ja typpeä sisältävä kasvusto kynnetään tai muokataan kokonaan maahan ennen seuraavan viljelykasvin viljelyä (Varis \& Kauppila 1992, Draycott ja Christenson 2003, Cherr ym. 2006). Viherlannoituksen vaikutuksen ratkaisee kasvilaji, kasvuaika, biomassan määrä, typpipitoisuus, viljelykiertoon sovittaminen ja viljelytekniikka (Känkänen 2009). Viherlannoituskasveiksi voidaan valita joko palkokasveja tai ei-palkokasveja, yksi- tai monivuotisia kasveja. Viherlannoituskasveiksi kannattaa valita viljelyvarmoja kasvilajeja, jotka tuottavat nopeasti runsaan biomassan. Kolmivuotisen timotei-puna-apila kasvuston juurista ja versoista jää maahan noin 9000 kg kuiva-ainetta (Känkänen 2009). Kasvilajien typpipitoisuus vaihtelee. Heinäkasvien typpipitoisuus on noin yksi prosentti ja palkokasveilla jopa neljä prosenttia (Känkänen ym. 2009). Varis \& Kauppila (1992) tekemissä kokeissa puna-apilakasvustosta maahan todettiin jäävän 90-150 kg N/ha. Typen vapautumista voidaan hillitä siirtämällä kasvuston muokkaminen maahan syys-lokakuulle tai kevääseen, kun viherlannoituksen jälkeen viljellään kevätkylvöistä kasvia (Känkänen 2009). Lisäksi maahan muokattu kasvimateriaali vilkastuttaa maan mikrobiston toimintaa. Tehokas mikrobien toiminta parantaa murujen kestävyyttä ja sitä kautta maan rakennetta. Syväjuurisilla kasveilla, kuten apiloilla, on välitön vaikutus maan rakenteeseen. Talven aikana viherlannoitusnurmi vähensi nitraattitypen huuhtoutumista (Baggs ym. 2000). Eri viljelykasvien viljely vaihtelevasti vähentää rikkakasvien, tautien ja tuholaisten torjuntatarvetta (Draycott ja Christenson 2003, Cherr ym. 2006).

Kokeen tarkoituksena oli selvittää viherlannoituksen vaikutusta sokerijuurikkaan sadon määrään ja sen laatuun sekä maan kuntoon.

\section{Aineisto ja menetelmät}

Koe järjestettiin viljelijän pellolla Tenholassa kasvukautena 2007-2009. Viljavuusarvot sokerijuurikaan kylvövuonna 2009 olivat keväällä ennen kylvöjä viherlannoituslohkolla pH 6,8, P 31,2 mg/l, K 126 mg/l, Ca 4550 mg/l, Mg 242 mg/l, Na 30 mg/l ja tavallisen lannoituslohkolla pH 7,1, P 26,1 mg/l, K 183 mg/l, Ca 4680 mg/l, Mg 209 mg/l, Na 36 mg/l. Maalaji oli molemmilla lohkoilla multava HeS. Viherlannoitusnurmi perustettiin vuonna 2007 ohra suojaviljaan. Timotei puna-apila seoksen kylvömäärä oli 12 kg/ha, jossa puna-apilan osuus oli 25 \%. Vuonna 2008 kasvusto murskattiin maahan kerran kasvukauden aikana. Syksyllä viherlannoitusnurmi ruiskutettiin glysfosaatilla ja lohko kynnettiin. Kokeessa viherlannoitusta verrattiin tavalliseen lannoituksen saaneeseen lohkoon, jolla oli viljelty vuonna 2007 juurikasta ja vuonna 2008 mallasohraa. Keväällä koealue tasausäestettiin viikkoa ennen kylvöä. Molempiin lohkoihin kylvettiin kaksi noin 250 m pituista ja 4.5 m levyistä kaista, joista toiselle annettiin $90 \mathrm{~kg} \mathrm{~N} / \mathrm{ha}$ ja toiselle $120 \mathrm{~kg}$ N/ha. (Nurmen NK 2). Lohkot kylvettiin 30.4. siemenetäisyydellä $24 \mathrm{~cm}$ ja rivivälillä $50 \mathrm{~cm}$. Lajikkeina olivat Nordika ja Hamilton (vain tuholaishavainnointia varten). Kasvinsuojelu tehtiin tilan normaaliohjelman mukaisesti. Keväällä havainnoitiin lohkojen maan kuivuminen silmämääräisesti. Kokeessa seurattiin taimettumista. Ennen kylvöä (20.4.), heinäkuun alussa (5.7.) ja elokuun lopulla (25.8.) otettiin maanäytteet nitraatti- ja ammoniumtyppimääritystä varten. Näytteet otettiin kaistasta, jolle annettiin 90 kg typpeä/ha. Näytteet säilytettiin pakasteessa ennen määritystä (Typpilaukku, Scandinavian Grow Products Oy, Suomi). Kasvukauden aikana seurattiin kasvuston 
lehtivihreän kehitystä SPAD-mittarilla (Minolta SPAD 502). Kasvustojen peittävyys-\% määritettiin elokuun lopulla. Kuoppatesti tehtiin elokuussa. Pintamaan vedenjohtavuus mitattiin $90 \mathrm{~kg}$ typpeä/ha saaneista kaistoista kaatamalla vettä noin $5 \mathrm{~cm}$ korkeudelta maahan painetun pyöreän ja pohjattoman sangon sisään ja mittamaalla aika, joka kului veden imeytymiseen maahan (Peltomaan laatutesti 2006). Viherlannoituksen vaikutusta tuholaisvioituksiin havainnoitiin eri siemenkäsittelyillä lajikkeilla (Hamilton-Poncho Beta-peittaus ja Nordika-Cruiser-peittaus). Lisäksi määritettiin silmämääräisesti Ramularia-lehtilaikkutaudin määrä. Ramularia-ruiskutuksia ei tehty koealueella. Syyskuussa nostettiin 4 x 10 rivimetriä jokaisesta Nordika lajikkeen kaistasta. Juurisato ja juurikkaan keskipaino määritettiin nostetuista näytteistä. Sadon laatua tutkittiin määrittämällä sokeri-, aminotyppi-, kalium- ja natriumpitoisuus sekä saanto-\% samoista näytteistä.

Koe toteutettiin osaruutukoe mallisena. Pääruututekijöinä olivat viherlannoitus ja tavallinen lannoitus, osaruututekijöinä typpilannoitusmäärät 90 ja 120 kg/ha. Lajiketta ei käytetty erillisenä osaruututekijänä, koska Hamilton lajiketta kylvettiin koekaistoihin vain yksi rivi per kaista, eikä siitä tehty sato havaintoja. Tulokset analysoitiin varianssianalyysillä käyttäen SAS-ohjelmiston GLM-proseduurilla. Käsittelyjen parittaiset vertailut tehtiin Tukey’n testillä merkitsevyystasolla $\mathrm{P}<0,05$.

\section{Tulokset ja tulosten tarkastelu}

Ennen kylvömuokkausta viherlannoituslohkolla maan kuivuminen oli nopeampaa ja kosteusolot olivat tasaisemmat kuin tavallisella lohkolla. Kasvit taimettuivat nopeammin ja kasvusto oli tasaisempi viherlannoituslohkolla kuin tavallisella lohkolla. Eri siemenpeittauskäsittelyillä ei ollut eroja taimipoltteeseen eikä tuholaisvioituksiin silmämääräisesti havainnoituna. Heinäkuun alussa (8.7.) kasvuston peittävyys-\% oli $85 \%$ viherlannoituslohkolla riippumatta typpilannoitusmäärästä (90 ja $120 \mathrm{~kg}$ N/ha). Tavallisella lannoituksella alhaisemmalla typpilannoituksella peittävyys oli $70 \%$ ja korkeammalla $80 \%$. Tulosten perusteella viherlannoitus nopeutti juurikkaan alkukasvua. Vastaavaa ero ei havaittu elokuun (15.8) mittauksessa, jossa kasvustojen peittävyydet olivat 100 $\%$.

Juurikaskasvuston SPAD-arvoissa ei ollut merkitseviä eroja eri typpilannoitustasojen välillä kasvukauden aikana (Kuva 1). Heinä-, elo- ja syyskuussa viherlannoitus antoi korkeimmat kasvuston SPAD-arvot (Kuva 1). SPAD-lukemat kuvaavat juurikkaan lehtivihreän määrää, joka puolestaan antaa tietoa juurikkaan mahdollisesta typpilannoitustarpeesta. Tulokset osoittavat, että viherlannoituslohkolla sokerijuurikkaalla oli kasvukauden aikana enemmän typpeä käytetävissään kuin tavallisella lannoituslohkolla. Sokerijuurikkaalla yleisen kasvukunnon kannalta optimaaliseksi SPAD-arvoiksi on arvioitu 37-41, kun seitsemän-kahdeksan lehteä on auki ja 42-46, kun yhdeksän tai useampi lehti on auki (Peltonen 1997). 


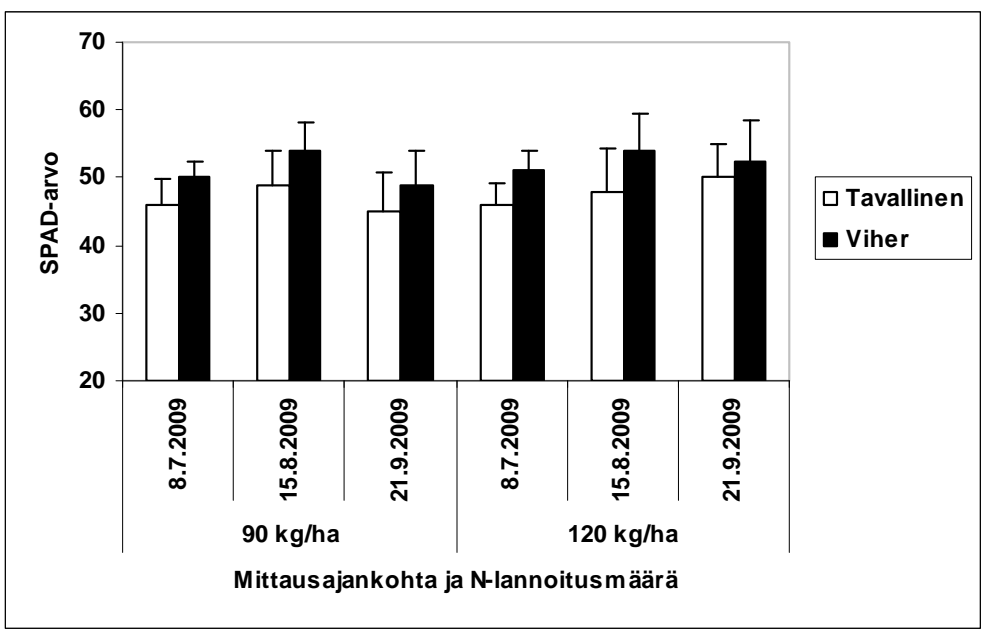

Kuva 1. SPAD-mittaustulokset viherlannoitus ja tavallisen lannoituksen kasvustosta typpilannoitusmäärillä 90 ja 120 kg/ha. Keskihajonta ilmoitettu palkilla pylväiden päällä.

Kasvukauden aikana seurattiin maan kuntoa mittaamaalla pintamaan vedenjohtavuus. Mittaus tehtiin $90 \mathrm{~kg}$ typpeä/ha saaneilta kaistoilta. Viherlannoituslohkolla pintamaan vedenjohtavuus oli kaksi kertaa suurempi $(4,8 \mathrm{~cm} / \mathrm{h})$ kuin normaalilannoituslohkolla $(2,1 \mathrm{~cm} / \mathrm{h})$. Tämä johtuu todennäköisemmin siitä, että viherlannoitusnurmen maahan muokkaminen ja apilan viljely parantaa maan rakennetta ja huokoistaa maata, jolloin maan veden läpäisykyky paranee. Lisäksi kuoppatestissä havaittiin selvästi, että kastematoja ja lieroja ja niiden tekeminä käytäviä oli muokkauskerroksessa enemmän viherlannoitetussa maassa kuin tavallisen lannoituksen saaneessa maassa.

Syyskuussa havainnoitiin Ramularia-lehtilaikkutaudin määrä juurikaskasvustossa. Viherlannoituslohkolla lehtitaudin määrä kasvustossa oli keskimäärin 5 \%. Tavallisella lannoituslohkolla lehtitautia esiintyi keskímäärin 18 \%. Tulos osoittaa, että viherlannoitusnurmi alensi lehtilaikkutautia. Lohkoilla Ramulariaa ei torjuttu kemiallisesti.

Maan liukoisen typen pitoisuutta seurattiin kasvukauden aikana $90 \mathrm{~kg}$ N/ha saaneista kaistoista. Ennen kylvöä sekä viherlannoituksella, että tavallinen lannoituksella maan nitraattityppipitoisuus oli $21 \mathrm{~kg} / \mathrm{ha}$. Heinäkuun alun mittaukseen mennessä maan liukoisen typen pitoisuudet olivat korkeammat kuin enen kylvöä. Viherlannoituslohkolla nitraattityppipitoisuus oli $70 \mathrm{~kg} \mathrm{~N} / \mathrm{ha}$ ja tavallisella lohkolla $56 \mathrm{~kg} \mathrm{~N} / \mathrm{ha}$. Kohonneeseen pitoisuuteen vaikuttavat tietysti lannoitteena annettu typpi, mutta myös maan oman mikrobitoiminnan vapauttama typpi. Lohkojen eroavaisuuteen tässä vaiheessa lienee syynä typen lisääntynyt mineralisoituminen viherlannoituslohkolla maan aikaisemman lämpenemisen vuoksi, sekä suuremman orgaanisen massan hajotus määrä. Syyskuun lopulla nitraattityppipitoisuus jälkeen aleni ja oli 7 kg N/ha sekä viherlannoituslohkolla että tavallisella lohkolla. Ammoniumtyppeä ei näytteistä löydetty.

Juurisadon määrää oli merkitsevästi korkeampi viherlannoituksella kuin tavallisella lannoituksella. Viherlannoitus tuotti noin $4500 \mathrm{~kg} / \mathrm{ha}$ suuremman sadon, kun typpilannoitusmäärä oli 90 kg/ha ja $9800 \mathrm{~kg} / \mathrm{ha}$ typpilannoituksella $120 \mathrm{~kg} / \mathrm{ha}$ (Taulukko 2) verrattaessa. Viherlannoitus tuotti noin 4500 kg/ha suuremman sadon, kun typpilannoitusmäärä oli 90 kg/ha ja 9800 kg/ha typpilannoituksella $120 \mathrm{~kg} / \mathrm{ha}$ (Taulukko 2) verrattaessa tavallisen lannoituksen korkeimpaan satoon. Tulokset osoittavat viherlannoituksen parantavan osaltaan juurikkaan sadontuottokykyä.

Sadon laatuominaisuuksista mikään ominaisuus ei eronnut merkittävästi pääruututekijöiden eikä osaruututekijöiden välillä. Tuloksista on kuitenkin havaittavissa suuntausta, jossa viherlannoitus parantaisi juurikassadon sokeripitoisuutta. Laatua heikentävistä tekijöistä aminotypen osuus viherlannoitus lohkolla kummallakin käsittelyllä vaikuttaisi korkeammalta, kuin tavallisen lannoituksen lohkolla. Vaikka ominaisuus ei eronnutkaan lohkojen välillä merkitsevästi, voidaan 
tuloksesta havaita aminotyppipitoisuuden jääneen alle $15 \mathrm{mg} / 100 \mathrm{~g}$ tavallisen lannoituksen lohkolla. Tämä tulkitaan juurikkaan viljelyssä usein merkkinä siitä, että kasvusto on alkanut kärsimään typen puutteesta kasvukauden loppupuolella. SPAD-mittausarvot eivät kuitenkaan tue tätä päätelmää, vaikkakin silmävarainen havainto pellolla osoitti tavallisen lannoituksen lohkon olleen viherlannoituslohkoa vaaleamman. Muut laatuun vaikuttavat ominaisuudet olivat kummallakin lohkolla erinomaisia.

Taulukko 2. Juurikkaan sato- ja laatutulokset viherlannoituksella ja tavallisella lannoituksella lannoitustyppimäärillä 90 ja $120 \mathrm{~kg} / \mathrm{ha} .$.

\begin{tabular}{|c|c|c|c|c|c|c|}
\hline & Sato tn/ha & Sokeri-\% & Saanto-\% & $\begin{array}{l}\text { Aminotyppi } \\
\mathrm{mg} / 100 \mathrm{~g}\end{array}$ & $\begin{array}{l}\text { Kalium } \\
\text { me }\end{array}$ & $\begin{array}{l}\text { Natrium } \\
\text { me }\end{array}$ \\
\hline \multicolumn{7}{|l|}{$\begin{array}{ll}\text { Osaruututekijä, } & \text { typpi- } \\
\text { lannoitus } & \\
\text { Viherlannoitus } & \end{array}$} \\
\hline 90 & $54,4 \mathrm{~b}$ & $17,8 \mathrm{a}$ & $87,2 \mathrm{a}$ & $15,2 \mathrm{a}$ & $4,0 \mathrm{a}$ & $0,3 a$ \\
\hline 120 & $57,9 \mathrm{a}$ & $17,7 \mathrm{a}$ & $87,1 \mathrm{a}$ & $16,0 \mathrm{a}$ & $4,0 \mathrm{a}$ & $0,3 \mathrm{a}$ \\
\hline \multicolumn{7}{|l|}{$\begin{array}{l}\text { Tavallinen lannoitus } \\
\text { Typpilannoitus kg/ha }\end{array}$} \\
\hline 90 & $49,9 c$ & $17,5 a$ & $86,6 a$ & $14,2 \mathrm{a}$ & $4,2 a$ & $0,3 a$ \\
\hline \multirow[t]{2}{*}{120} & $48,1 \mathrm{bc}$ & $17,5 \mathrm{a}$ & $86,4 a$ & $13,2 \mathrm{a}$ & 4,3a & 0,3a \\
\hline & \multicolumn{6}{|c|}{$\begin{array}{l}\text { Pystysarakkeiden eri kirjaimet eroavat toisistaan tilastollisesti merkitsevästi } \\
\mathrm{P}<0.05\end{array}$} \\
\hline \multicolumn{7}{|l|}{ Yhdysvaikutus } \\
\hline Viherlannoitus & $56,2 \mathrm{a}$ & $17,7 \mathrm{a}$ & $87,2 \mathrm{a}$ & 15,6 & 4,0a & 0,3a \\
\hline \multirow[t]{2}{*}{ Tavallinen lannoitus } & $49,0 \mathrm{~b}$ & $17,5 \mathrm{a}$ & $86,5 a$ & 13,7 & 4,3a & 0,3a \\
\hline & \multicolumn{6}{|c|}{$\begin{array}{l}\text { Pystysarakkeiden eri kirjaimet eroavat toisistaan tilastollisesti merkitsevästi } \\
\mathrm{P}<0.05\end{array}$} \\
\hline
\end{tabular}

\section{Johtopäätökset}

Tulosten perusteella yksivuotinen viherlannoitusnurmi soveltuu hyvin sokerijuurikkaan viljelykiertoon ja sen monipuolistamiseen. Viherlannoitus nopeuttaa juurikkaan alkukasvua ja taimettuminen on tasaisempaa. Ennen kaikkea se lisää juurikkaan sadontuottokykyä todennäköisesti kesän aikana maasta vapautuvan typen ansiosta ja maan kasvukunnon paranemisen kautta. Pitkän kasvukauden kasvina juurikas kasvaa ja ottaa ravinteita myöhään syksyyn ja pystyy sen vuoksi tehokkaasti hyödyntämään viherlannoitusnurmesta mineralisoituvan typen. Tämä maasta vapautuva typpi ei tulosten valossa näyttäisi myöskään olevan mikään ongelmatekijä sadon laadun suhteen. Tutkimus jatkuu vuoden 2010 loppuun, jonka jälkeen voitaneen antaa tarkempia typpilannoitussuosituksia viherlannoituksen jälkeiselle juurikaskasvustolle. Kokeen tuloksia hyödynnetään edelleen sokerijuurikkaan kilpailu- ja sadontuottokyvyn parantamisessa. 


\section{Kirjallisuus}

Baggs, E.M., Watson, C.A. \& Rees, R.M. 2000. The fate of nitrogen from incorporated cover crop and green manure residues. Nutreint Cycling in Agroecosystems 56:153-163.

Cherr, C.M., Scholberg, J.M.S. \& McSorley, R. 2006. Green manure approaches to crop production: A synthesis. Agronomy Journal 98:302-319.

Draycott, P.A \& Christenson, D.R. 2003. Organic manures, green manuring and organic production 107122.Teoksessa: Nutrients for Sugar Beet Production: Soil Plant Relationships. Cromwell Press, Trowbridge.

Känkänen, H. 2009. Viherlannoituksessa on tiedettävä tavoite. Juurikassarka 1:16-17.

Känkänen, H., Kymäläinen, M. Nykänen, A. 2009. Viherlannoituksesta enemmän tehoa. Maaseudun Tiede 3:12.

Peltomaan laatutesti. 2006. Pintamaan vedenjohtavuuden mittaus.

http://www.virtuaali.info/efarmer/peltomaan_laatutesti/

Peltomaan laatutesti. 2006. Kuoppahavainnot. http://www.virtuaali.info/efarmer/peltomaan_laatutesti/

Peltonen, J. 1997. Lisätypen tarve selviää lehtivihreämittarilla. Leipä leveämmäksi 3/97:16.

Varis, E. \& Kauppila, R. 1992. Viherlannoituskokeiden tuloksia vuosilta 1979-87. Helsingin yliopiston Kasvintuotantotieteen laitos. Kasvinviljelytieteen julkaisuja no 30. Yliopistopaino. 260 s. 